\title{
Cytological Smear and Cell Block Versus Tissue Biopsies in the Diagnosis of Malignant Tumours in Non-Gynaecologic Specimens
}

\author{
Nasar Alwahaibi ${ }^{1 *}$, Asmaa Alghallabi ${ }^{2}$, Shadia Alsinawi ${ }^{3}$, Najat Aldairi ${ }^{4}$
}

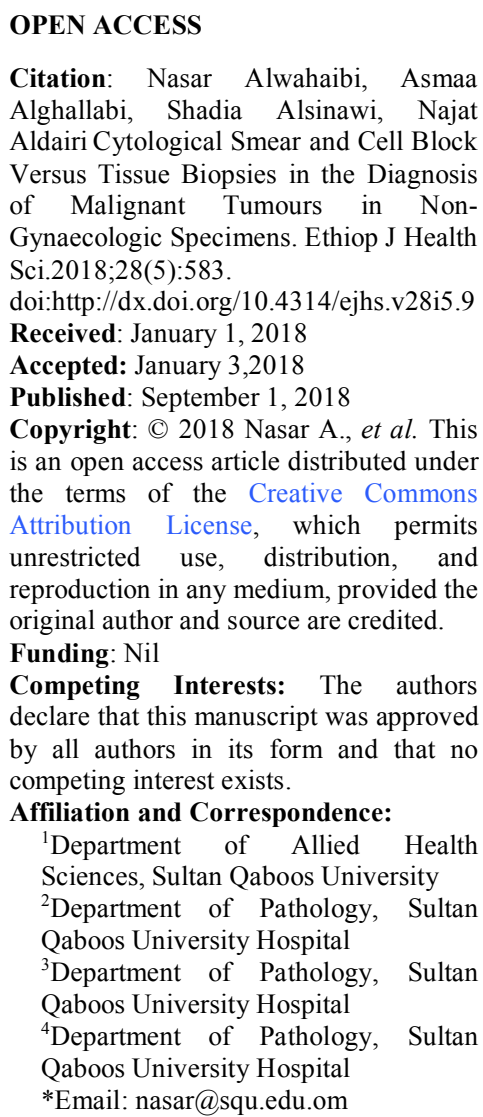

\section{ABSTRACT}

BACKGROUND: Cytological smear and cell block (CB) are routinely used to diagnose non-gynaecologic specimens. However, there is scanty information in the literature to compare cytological smear and $C B$ with the corresponding tissue biopsies. This study is aimed at evaluating the accuracy of cytological smear and $C B$ in the diagnosis of malignant tumours in non-gynaecologic specimens.

MATERIALS AND METHODS: A total of 70 malignant cases were subjected to cytological smear and $C B$. Corresponding histopathology was also included. The most frequent immunomarkers found between $C B$ and tissue biopsies were also correlated. Accuracy, sensitivity, specificity, positive predictive value, negative predictive value, false positive and false negative values were analyzed for each method.

RESULTS: The accuracy, sensitivity and positive predictive value for cytological smear were $92.8 \%, 100.0 \%$ and $92.9 \%$, whereas for $\mathrm{CB}$ were $91.4 \%, 98.4 \%$ and $92.7 \%$, respectively. In $\mathrm{CB}$ method, the accuracy, sensitivity and positive predictive value for $\mathrm{CK} 7$ were $88.9 \%, 91.7 \%$ and $95.6 \%$, whereas for $C K 5 / 6$ were $75 \%, 100 \%$ and $57.1 \%$, respectively.

CONCLUSION: Cytological smear and $C B$ are very sensitive and accurate in the detection of malignant tumours in nongynaecologic specimens. Additional corresponding tissue biopsies should be re-evaluated.

KEYWORDS: Accuracy, cell block, cytological smear, malignancy, immunomarkers, sensitivity

\section{INTRODUCTION}

Cytological smears and cell blocks (CB) play important roles in the diagnosis of non-gynaecological cytopathology specimens such as urine, abdominal (ascetic, peritoneal), cerebrospinal fluid (CSF), cyst fluid, sputum, synovial, pleural and pericardial fluid. In cytological smear, the sample is either smeared on a glass slide or made on a monolaye, and it is subsequently stained with the following stainsPapanicolaou, Diff quick and heamatoxylin and eosin. Samples of CB 
are fixed in $10 \%$ neutral buffered formalin and then treated as a tissue block. $\mathrm{CB}$ is used to establish a more definitive diagnosis adjuncts to cytological smear especially in categorization of tumor (1). Cytological smear is superior to the CB, the cell examined by cytological smear is much larger than that examined by $\mathrm{CB}$, quick in process and less expensive (2). However, overlapping of the cells is a limitation in cytological smear. In comparison, multiple sections form $\mathrm{CB}$ can be used for special stains and immunocytochemistry methods. Those methods increase the sensitivity of the cytodiagnosis of malignant yield when compared with the cytological smear method (3). Disadvantages of CB include some cells are lost during processing, preparation takes longer time about 48 hours, and the presence of artifacts.

In the last few years, cytological smear has improved. Monolayer preparations such as ThinPrep ${ }^{\circledR}$ processor, AutoCyte PREPTM system or other similar processors have been introduced to prevent air drying artefact, reduce background material and increase cellularity. Thus, cytological misdiagnosis has reduced drastically (4). Similarly, many CB preparations have been introduced. There is scanty information in the literature to compare cytological smear and $\mathrm{CB}$ with corresponding tissue biopsies. This study evaluates the accuracy of cytological smear and $\mathrm{CB}$ in the diagnosis of malignant tumours in nongynaecologic specimens.

\section{MATERIALS AND METHODS}

Non-gynecologic fluid specimens were collected from Pathology Department from 2007 to 2015. Inclusion criteria included malignant specimens of pericardial, pleural, peritoneal fluid, bronchial washing, urine, sputum, cyst aspiration, CSF and pelvic fluid. Each specimen must have a cytological smear, CB and tissue biopsy as a gold standard. CB that lacks haematoxylin and eosin (H\&E) slide, a $3 \mu \mathrm{m}$ section was cut using a rotary microtome (RM2135, Leica Microsystems AG, Wetzler, Germany), and then stained by H\&E method (5). Exclusion criteria included benign cases, fine needle aspiration (FNA) samples and the absence of $\mathrm{CB}$ or tissue biopsy. For immunohistochemistry (IHC) and immunocytochemistry (ICC) stains, only those immunomarkers which were found comparable in tissue biopsy and $\mathrm{CB}$, respectively, were included in this study. However, other immunomarkers which where found in only one stain were excluded. Ethical approval was obtained from the Medical Research Committee and Ethics Committee, College of Medicine and Health Sciences, Sultan Qaboos University, Oman.

The data were analyzed using Statistical Package for the Social Science (SPSS) software version 23 (Chicago, USA, SPSS Inc.). With the assumption that suspicious cases were malignant, calculations for accuracy, sensitivity, specificity, positive predictive value (PPV), negative predictive value (NPV), false positive and false negative values were used for analysis of the smear and $\mathrm{CB}$ compared to the tissue biopsy as a gold standard method.

\section{RESULTS}

Only 70 malignant cases fitted with our criteria and those include cytological smear, $\mathrm{CB}$ and corresponding tissue biopsies. The average age was 51.9 years, minimum of 5 years and maximum of 90 years. Males were present in $51.4 \%$ and females in $48.6 \%$.

Histopathological examination of those cases revealed 62 malignant cells, and three suspicious of malignancy, while five cases were diagnosed as benign. In cytological smear, there were 52 cases diagnosed as malignancy and 13 as suspicious of malignancy with sensitivity of $100 \%$ and no false negative cases. The accuracy of cytological smear was $92.8 \%$, and positive predictive value was $92.9 \%$. In $\mathrm{CB}$, there were 56 cases diagnosed as malignancy and 13 as suspicious of malignancy with sensitivity of $98.4 \%$, Also, one case was diagnosed falsely as benign and five cases were diagnosed as malignancy while they were benign. The accuracy of $\mathrm{CB}$ was $91.4 \%$ and positive predictive value was $92.7 \%$ (Table 1). 
Table 1: Correlation of findings between cytological smear, cell block and tissue biopsy in the diagnosis of 70 malignant non-gynaecologic specimens.

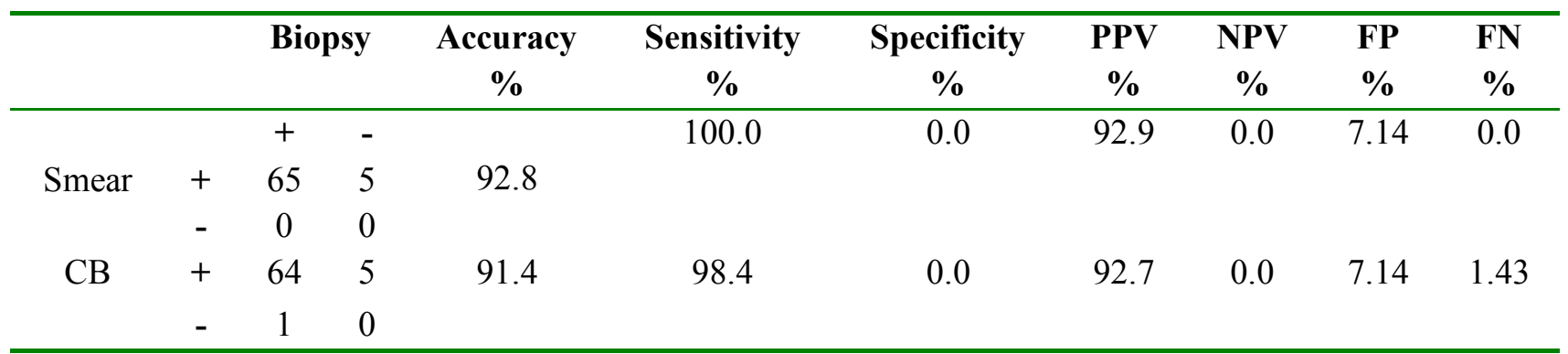

CB: cell block, PPV: positive predictive value, NPV: negative predictive value, FP: false positive, FN: false negative

For CK7 immunostaining, there were 27 matched samples between $\mathrm{CB}$ and tissue biopsy, sensitivity was $91.7 \%$ while positive predictive value was 95.6\%. Among the other immunomarkers, CK20 followed by thyroid transcription factor 1 (TTF1) showed the highest specificity with $86.7 \%$ and
$83.3 \%$, respectively. The sensitivity for BerEP4 was $75.0 \%$. For CK5/6 immunostaining, there were 12 matched samples between $\mathrm{CB}$ and tissue biopsy, sensitivity was $100 \%$, and no false negative cases. Other parameters are shown in Table (2).

Table 2: Correlation of different immunomarkers using cell block and tissue biopsy.

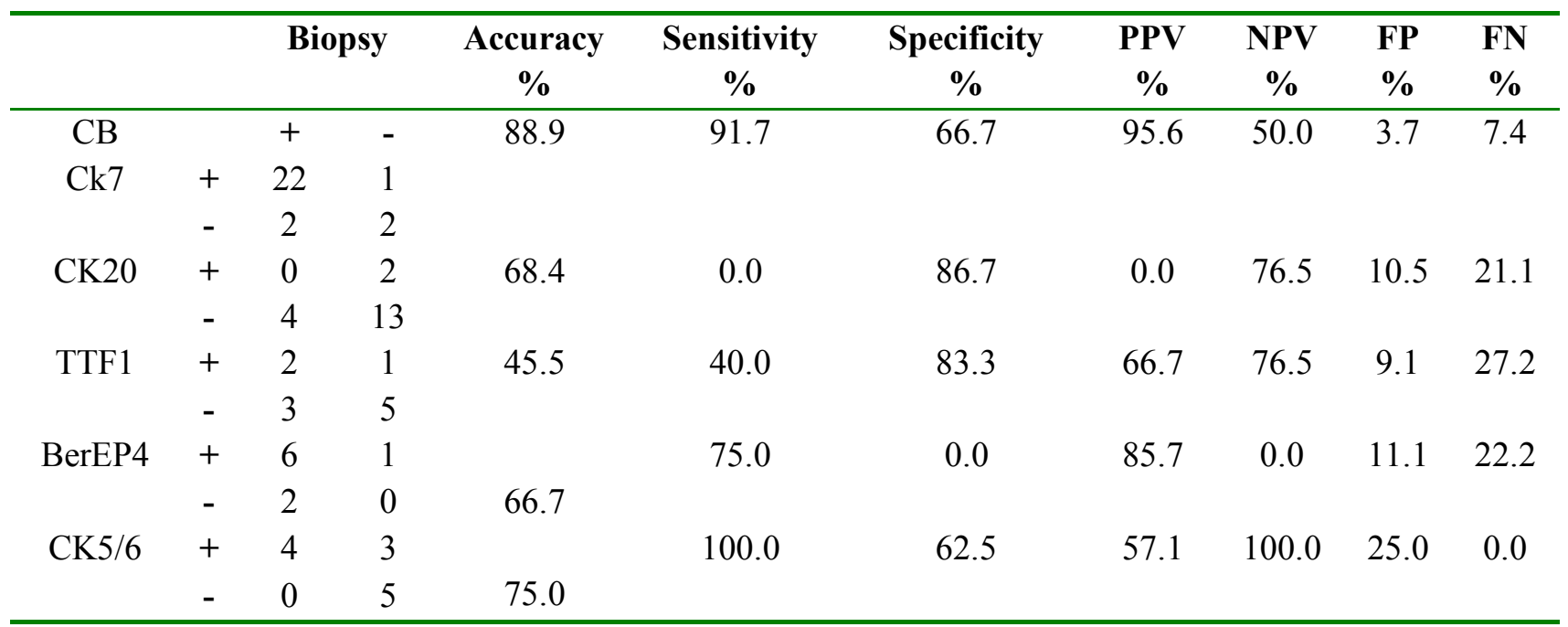

CB: cell block, CK: cytokeratin, TTF1: thyroid transcription factor 1, PPV: positive predictive value, NPV: negative predictive value, FP: false positive, FN: false negative

\section{DISCUSSION}

This study evaluated the accuracy of cytological smear and $\mathrm{CB}$ in the final diagnosis of malignancy and correlated the results with the gold standard method which is the tissue biopsy. The diagnosis of tissue biopsies is the traditional method; however, it is invasive, lengthy, unsafe and costly. Some studies show that the use of CB method increases the final diagnostic accuracy. This additional diagnostic yield can vary between $10 \%$ (6), 12\% (7), 13\% (8) and 15\% (3). The current

DOI: http://dx.doi.org/10.4314/ejhs.v28i5.9 
study showed that the diagnosis made by CB was almost similar to cytological smear diagnosis.

In this study, out of 70 cases, cytological smear showed $100 \%$ sensitivity. This finding is higher than the results of other studies, which found $71.42 \%$ (50/70) positive malignant cells by cytological smear (1). In addition, cytological smear in our study did not report any case of false negative. This finding is inline with the findings of which reported that no false negative cases were found in the diagnosis of fine needle aspiration cytology for breast, thyroid, lung and lymph node compared with the histopathology diagnosis (9). Our study also showed a PPV for cytological smear was high (92.9\%). However, only five cases were reported as false positive.

Similarly, Out of 70 cases, CB showed $98.4 \%$ sensitivity. This finding is slightly higher than those reported by other studies which reported $85.7 \%(60,70)$ cases of positive malignant tumours examined by CB (8). There was one case reported as false negative and five cases reported as false positive with 1.43 and $7.14 \%$, respectively. The latter was similar with that which was found in the diagnosis of cytological smear. Our study also showed a PPV for CB was high $(92.7 \%)$.

Immunomarkers are generally used to help in the diagnosis of the type and site of tumor origin and for prognostic and treatment evaluation. Immunocytochemistry can be done in smear or CB. However, cytological smear showed a high background staining as encountered in $66 \%$ of cases, most evident in three-dimensional clusters of cells. In comparison, CB showed less background staining as encountered in only $17 \%$ cases (10). Also, multi sections can be obtained from $\mathrm{CB}$, so several types of markers can be done. It is important to note that the histological role in grading immunomarkers is well established while cytological grading is not widely practiced (11). The current study compared the results of CK7, CK20, TTF1, BerEP4, CK5/6 between CB and tissue biopsy. These markers were the most commonly used ones in both methods. CK7 has a high sensitivity $(91.7 \%)$, and it was very good in predicting the positive cases as PPV showed $95.6 \%$. It was reported that $\mathrm{CK} 7$ was expressed in $96.6 \%$ of total 329 gastric carcinoma specimens
(12). In comparison, CK20 has $0.0 \%$ sensitivity and a high chance to miss the positive cases. However, it has a high specificity rate $(86.7 \%)$ and a low chance to miss the negative cases $(76.5 \%)$. CK20 is a good marker to exclude adenocarcinoma arising from epithelia such as colorectal cancer, transitional cell carcinoma and Merkel cell carcinoma (13). The difference between the results of CK7 and CK20 might be the small sample size or the type and duration of fixative which was not suitable for CK20 that might lead to antigen destruction. There are several factors that might affect immunoreactivity in immunocytochemistry method; those involved in fixation include the duration, $\mathrm{pH}$, and type of fixative used. Others involve in tissue processing, include temperature and the duration of the dehydration and wax infiltration steps (14).

This study also showed that the sensitivity for CK5/6 was $100.0 \%$. This finding is inline with the results of which reported that CK5/6 is detected in $97.0 \%$ of mesothelioma using tissue biopsy (15). BerEP4 is a cell surface glycoprotein that presents on human epithelial cells but lacking on the mesothelium. A study reported over 120 adenocarcinoma and $103(86.0 \%)$ cases showed membranous BerEP4 positivity (16). In this study, the sensitivity of BerEP4 was $75.0 \%$; however, over nine samples, one case was missed to diagnose true negative by $\mathrm{CB}$ method and that might because of low sample size or might because of cross reactivity. Thyroid transcription factor (TTF-1) is a homeodomain -containing transcription factor that is expressed in pulmonary epithelial cells of thyroid, and pulmonary and has been demonstrated in adenocarcinoma of the thyroid, lung and small cell lung carcinoma (17). It was reported that $96 \%$ of the 28 small lung carcinoma were positive for TTF1 in tissue biopsy (18). In this study, TTF-1 had a high specificity $(83.3 \%)$ and a low sensitivity $(40.0 \%)$ in 11 samples, so it had a low chance to miss the negative cases. Low sensitivity might be due to the TTF1 affected by CB preparation, or it might be over fixed.

One of the drawbacks of CB method is the possible loss of material during preparation, fixation and histoprocessing. However, we did not

DOI: http://dx.doi.org/10.4314/ejhs.v28i5.9 
lose any material in all CBs. There are different methods of making $\mathrm{CB}$ such as plasma thrombin clot method, bacterial agar method, compact block technique and cell block from milipore filter method (6). Each method has its own advantages and disadvantages. In addition, different fixatives are used for different $\mathrm{CB}$ preparations. In this study, we used a compact block technique with $10 \%$ formalin as a fixative to prepare CB.

In conclusion, this study showed that cytological smear and $\mathrm{CB}$ were very sensitive and accurate in the detection of malignant tumours in non-gynaecologic specimens. Additional corresponding tissue biopsies should be reevaluated.

\section{ACKNOWLEDGEMENTS}

We would like to thank all staff in the Pathology Department at Sultan Qaboos University Hospital, Muscat, Sultanate of Oman, for their cooperation and help in providing the data.

\section{REFERENCES}

1. Nathan NA, Narayan E, Smith MM, Horn MJ. Cytology-improved preparation and its efficacy in diagnostic cytology. Am J Clin Pathol, 2000;114:599-606.

2. Noda Y, Fujita N, Kobayashi G, Itoh K, Horaguchi J, Takasawa O, et al. Diagnostic efficacy of the cell block method in comparison with smear cytology of tissue samples obtained by endoscopic ultrasoundguided fine-needle aspiration. $J$ Gastroenterol, 2010;45:868-75.

3. Shivakumarswamy U, Arakeri SU, Karigowdar MH, Yelikar B. Diagnostic utility of the cell block method versus the conventional smear study in pleural fluid cytology. J Cytol, 2012;29:11-5.

4. Alwahaibi N, Alnoumani N, Bai U. Comparison of ThinPrep ${ }^{\circledR}$ and conventional preparations for peritoneal and pleural cytology smears. Annu Res Rev Biol, 2014;4:3139-49.

5. Bancroft JD, Gamble M. Theory and Practice of Histological Techniques. $6^{\text {th }}$ ed. Churchill
Livingstone Elsevier: Philadelphia; 2008. p.123.

6. Bhanvadia VM, Santwani PM, Vacbhani JH. Analysis of diagnostic value of cytological smear method versus cell block method in body fluid cytology: study of 150 cases. Ethiop J Health Sci, 2014;24:125-31.

7. Liu K, Dodge K, Glassgow BJ, Layfield LJ. Comparison of smears, cytospin \& cell block preparation in diagnostic \& cost effectiveness. Diagn cytopathol, 1998;19:70-4.

8. Thapar M, Mishra RK, Sharma A, Goyal V, Goyal V. Critical analysis of cell block versus smear examination in effusions. $J$ Cytol, 2009;26:60-4.

9. Basnet S, Talwar OP. Role of cell block preparation in neoplastic lesions. J Pathol Nepal, 2012;2:272-6.

10. Fetsch PA, Simsir A, Brosky K, Abati A. Comparison of three commonly used cytologic preparations in effusion immunocytochemistry. Diagn Cytopathol, 2002;26:61-6.

11. Handa U, Kumar A, Kundu R, Dalal U, Mohan $\mathrm{H}$. Evaluation of grading and hormone receptor immunostaining on fi ne needle aspirates in carcinoma breast. $J$ Cytol, 2015;32:1-5.

12. Kim MA, Lee HS, Yang HK, Kim WH. Cytokeratin expression profile in gastric carcinomas. Hum Pathol. 2004;35:576-81.

13. Moll R, Lowe A, Laufer J, Franke WW. Cytokeratin 20 in human carcinomas. A new histodiagnostic marker detected by monoclonal antibodies. Am $J$ Pathol, 1992;140:427-47.

14. Williams JH, Mepham BL, Wright DH. Tissue preparation for immunocytochemistry. $J$ Clin Pathol, 1997;50:422-8.

15. Shield PW, Koivurinne K. The value of calretinin and cytokeratin $5 / 6$ as markers for mesothelioma in cell block preparations of serous effusions. Cytopathology, 2008;19:21823.

16. Gaffey MJ, Mills SE, Swanson PE, Zarbo R, Shah A. Wick, M. Immunoreactivity for BEREP4 in adenocarcinomas, adenomatoid 
tumors, and malignant mesotheliomas. $\mathrm{Am} \mathrm{J}$ Surg Pathol, 1992;16:593-9.

17. Jones TD, Kernek KM, Yang XJ, LopezBeltran A, MacLennan GT, Eble JN, et al. Thyroid transcription factor 1 expression in small cell carcinoma of the urinary bladder: an immunohistochemical profile of 44 cases. Hum Pathol, 2005;36:718-23.

18. Ordonez NG. Value of thyroid transcription factor-1 immunostaining in distinguishing small cell lung carcinomas from other small cell carcinomas. Am $J$ Surg Pathol, 2000;24:1217-23. 